\title{
Educação especial e educação de jovens e adultos: uma interface em construção?
}

\author{
Rosângela Martins Cabral* \\ Luciane Guimarães Batistella Bianchini** \\ Taisa Grasiela Gomes Liduenha Gonçalves***
}

\section{Resumo}

A Educação Especial (EE) e a Educação de Jovens e Adultos (EJA) apresentam semelhanças históricas de negação ao direito educacional e, recentemente, essas duas áreas têm se deparado com encontros e desafios. A partir dessa ideia questionamos: como vem sendo construída a EJA para os alunos da EE? Por meio de uma pesquisa qualitativa e quantitativa com análise bibliométrica, o presente estudo objetivou verificar se a produção acadêmica brasileira tem discutido essa temática. Também buscou identificar a percepção do processo de escolarização na EJA Especial por dois alunos com deficiência intelectual e física, estudantes de uma escola estadual paranaense, através de uma entrevista semiestruturada. Os resultados revelaram como pouco expressivo o número de trabalhos sobre o tema, que totalizaram quatorze, no período de 2010 a 2016. Com relação às percepçóes dos alunos sobre sua trajetória escolar, eles destacaram que a visão orgânica e assistencialista, seja da família ou da escola, prevalece sobre suas reais possibilidades. Concluiu-se que a interface entre EE e EJA continua apresentando reflexóes sobre a efetividade das políticas, das interaçóes sociais e das práticas inclusivas.

Palavras-chave: Educação Especial; Educação de jovens e adultos; Escolarização.

\footnotetext{
* Mestre em Ensino pela Universidade Norte Paraná (UNOPAR), Londrina, Paraná, Brasil.

** Doutora em Psicologia pela Universidade Estadual Paulista Júlio de Mesquita Filho. São Paulo, São Paulo Brasil

*** Doutora em Educação Especial pela Universidade Federal de São Carlos. São Carlos, São Paulo, Brasil.
} 


\section{Special education and youth and adult education: an interface under construction?}

\section{Abstratc}

Special Education (EE) and Youth and Adult Education (EJA) present historical similarities of denial of educational rights, and recently these two areas have met encounters and challenges. From this idea, we ask: how has EJA been constructed for EE students? Through a qualitative and quantitative research with bibliometric analysis, the present study aimed to verify if the Brazilian academic production has discussed this theme. We also sought to identify the perception of the schooling process in the Special EJA of two students with intellectual and physical disabilities, from a state school in the state of Paraná, through a semi-structured interview. The results revealed how inexpressive the number of papers on the subject is, which totaled fourteen in the period from 2010 to 2016. Regarding the students' perceptions about their school trajectory, they emphasized that the organic and assistentialist view, be it from the family or the school, prevails over their real possibilities. It was concluded that the interface between EE and EJA continues to reflect on the effectiveness of policies, social interactions and inclusive practices.

Keywords: Special education; Youth and adult education; Schooling.

\section{Educación especial y educación de jóvenes y adultos: ¿una interfaz en construcción?}

\section{Resumen}

La Educación Especial (EE) y la Educación de Jóvenes y Adultos (EJA) presentan semejanzas históricas frente a la negación del derecho educativo. Recientemente, estas dos áreas se han enfrentado a encuentros y desafíos. A partir de esa idea nos preguntamos: ¿cómo se está construyendo la EJA para los alumnos de la EE?. Por medio de una investigación cualitativa y cuantitativa con el análisis bibliométrico, el presente estudio tuvo como objetivo verificar si la producción académica brasileña ha discutido esa temática. De igual modo, se buscó a través de una entrevista semi estructurada identificar la percepción del proceso de escolarización en la EJA Especial, en dos estudiantes con discapacidad intelectual y física de una escuela estatal paranaense. Los resultados evidenciaron poca relevancia en el número de trabajos sobre el tema, siendo totalizados catorce, en el período de 2010 a 2016. Con respecto a las percepciones de los estudiantes sobre su trayectoria escolar, se destacó que la visión orgánica y asistencialista, de la familia o de la escuela, prevalece sobre sus posibilidades reales. Se concluyó que la interfaz entre EE y EJA continúa presentando reflexiones sobre la efectividad de las políticas, de las interacciones sociales y de las prácticas inclusivas.

Palabras clave: Educación especial; Educación de jóvenes y adultos; escolarización. 


\title{
Introdução
}

\author{
"Não há educação fora das sociedades humanas e não há homem \\ no vazio" (FREIRE, 1976, p.35).
}

A epígrafe ilustra que as condições vivenciadas pela classe trabalhadora são decorrentes de uma estrutura social governada por uma elite. Desse modo, a não efetivação dos direitos sociais, dentre eles a educação, significa retirar a possibilidade de transformação da realidade.

Nesse direcionamento, delimitou-se este estudo na Educação de Jovens e Adultos (EJA) e na Educação Especial (EE), por terem sido ambas criadas no Brasil devido a não universalização da educação formal. Assim, essas modalidades de ensino constituíram-se a partir de práticas assistencialistas e políticas compensatórias.

A interface entre EE e EJA está presente na legislação (BRASIL, 1996, 2008) e os indicadores educacionais revelam a ampliação do atendimento aos alunos público-alvo da EE na EJA, inclusive em classes e instituições especiais (GONÇALVES, 2012; MELETTI; RIBEIRO, 2014; HAAS; GONÇALVES, 2015).

Desse modo, esta pesquisa se dividiu em dois momentos. O primeiro objetivou verificar se a interface entre EE e EJA tem sido discutida no Banco de Teses da Coordenação de Aperfeiçoamento de Pessoal de Nível Superior (Capes). Em seguida, o estudo tentou identificar a percepção do processo de escolarização na EJA Especial por dois alunos, ambos com deficiência intelectual e física, por meio de uma entrevista semiestruturada. A questão norteadora de nossas discussôes foi: como vem sendo construída a EJA para os alunos da EE?

\section{EJA: possibilidade de escolarização ou espaço de desaparecimento da pessoa com deficiência?}

Ao iniciar a discussão sobre a construção da EJA no Brasil, há que se rever o conceito de analfabetismo e as condiçóes da realidade dos alunos que frequentam essa modalidade de ensino.

Segundo o Parecer CNE/CEB n. 11/2000 a "EJA representa uma dívida social não reparada para com os que não tiveram acesso a e nem domínio da escrita e leitura como bens sociais, na escola ou fora dela, e tenham sido a força de trabalho empregada na constituição de riquezas e na elevação de obras públicas" (BRASIL, 2000, p.5). Assim, o analfabetismo está incutido à estrutura política e econômica, evidenciando a desigualdade social e, consequentemente, a não apropriação do conhecimento formal (FERRARO, 2004). Há que se refletir sobre a realidade da classe trabalhadora e sobre a educação destinada a ela.

Baseando-se nos dados do Instituto Brasileiro de Geografia e Estatística (IBGE) de 2010 sobre o nível de instrução da população brasileira a partir dos 15 anos, Gonçalves, Meletti e Santos (2015) identificaram que 44,9\% das pessoas se declararam sem instrução ou com ensino fundamental incompleto. Isso significa que há um estreitamento para os níveis mais elevados de educação escolar, e a não efetivação de um direito constitucional, sendo que o ensino deve ser ministrado "com igualdade de condiçóes para o acesso e permanência na escola” (BRASIL, 1988). 
Essas pessoas acima dos 15 anos que não tiveram acesso à educação formal ou o tiveram com repetições e evasões retornam à EJA na busca pelo direito que lhes foi negado. Nessas circunstâncias, assistimos, no país, o crescente número de matrículas de alunos público-alvo da EE nessa modalidade de ensino (GONÇALVES, 2012).

Nesse direcionamento, a presença do aluno público-alvo da EE na EJA pode significar mais um espaço de acesso e conhecimento ao longo da vida. Por outro lado, pode significar também um espaço de desaparecimento do sujeito, quando não há uma intencionalidade pedagógica voltada para a emancipação dos jovens e adultos. Outros fatores podem contribuir para isso, tais como políticas de governo temporárias, a precariedade na formação docente inicial e continuada, a falta de infraestrutura e as más condiçôes do trabalho docente.

Portanto, questionamos: a EJA está se consolidando como mais um espaço de segregação aos alunos da EE ou como uma possibilidade de transformação social, haja vista uma disposição, em nível nacional, de uma estrutura denominada EJA Especial ocorrendo em classes e instituiçóes especiais? Isso pode parecer um retrocesso, ao tangenciar as políticas de inclusão (BRASIL, 2008).

Diante desse cenário, apresenta-se o percurso metodológico da pesquisa.

\section{Caminhos metodológicos}

Inicialmente, foi realizado um levantamento da produção no Banco de Teses e Dissertaçôes da Capes ${ }^{1}$, em busca de estudos realizados sobre a "Educação de jovens e adultos especial", com o intuito de verificar os avanços e as lacunas existentes, possibilitando, dessa forma, discussão e reflexão sobre a temática estudada.

Para tanto, baseamo-nos no estudo bibliométrico que, segundo Hayashi et al. (2007), é um instrumento que vem sendo utilizado por diversas áreas do conhecimento como metodologia para a obtenção de indicadores de avaliação da produção científica.

Os dados (coletados no mês de março de 2017 e sem delimitar um período) foram organizados em uma planilha de Excel, conforme as orientaçóes de Hayashi (2013) e Silva, Hayashi e Hayashi (2011).

Como referência de busca, elegeram-se os descritores: "Educação Especial EJA", "Inclusão Educação de Jovens e Adultos", "Inclusão EJA", "Deficiência EJA", "Deficiência Educação de Jovens e Adultos", "Educação de Jovens e Adultos educaçáo especial", "educação de jovens e adultos deficientes", "educação jovem adulto deficiente", "educação jovem deficiente", "educação especial educação de jovens e adultos". Apesar de selecionarmos um conjunto de descritores que condizem à temática deste estudo, infelizmente, não é possível atingir todos os trabalhos que estão no banco de teses e dissertaçôes da Capes. Isso porque há muita variação na escolha das palavras-chave pelos autores das teses e dissertaçôes ${ }^{2}$. 
O segundo momento da pesquisa foi a realização de uma entrevista semiestruturada com dois adultos, ambos com deficiência intelectual e física, sendo um concluinte e outro estudante do ensino médio na modalidade EJA Especial, em uma escola estadual de um município paranaense ${ }^{3}$.

As entrevistas foram realizadas com o auxílio de um gravador na própria escola que oferta EJA Especial. Depois, transcreveu-se na íntegra o conteúdo da entrevista e realizou-se a textualização, conforme propôe Caiado (2003).

\section{Resultados e discussão}

Apresentaremos, a seguir, os resultados da pesquisa realizada no Banco de Teses e Dissertaçóes da Capes sobre a interface entre EE e EJA. Na sequência, expomos os dados da realidade sobre a EJA Especial, a partir do relato de dois alunos com deficiência intelectual e física.

\section{A educação para jovens e adultos com deficiência na produção acadêmica}

O resultado inicial dessa coleta apontou para a existência de 16 estudos. A partir da leitura dos trabalhos, buscando o enfoque sobre a educação para jovens e adultos com deficiência e efetuando a exclusão dos registrados duplicados e daqueles que não se enquadravam no objetivo da pesquisa, foram selecionados um total de 14 trabalhos, no período de 2010 a 2016.

Desses, nove são dissertaçôes de mestrado e cinco são teses de doutorado. Desse modo, a temática é recente no meio científico, sem uma produçáo expressiva.

Ao verificar a distribuição das pesquisas segundo a dependência administrativa das instituições de ensino superior, identificamos que sete trabalhos foram defendidos em universidades federais, cinco na esfera estadual e duas na particular.

No que se refere à distribuição por região brasileira, oito trabalhos foram realizados na Sudeste, três no Sul, dois no Nordeste e um no Norte. interface.

$\mathrm{Na}$ sequência, serão apresentados os 14 trabalhos encontrados que tratam da

Quadro 1 -Teses e dissertaçôes sobre a interface EE e EJA

\begin{tabular}{|c|c|c|c|c|}
\hline Autor (a) & Nível & Orientador (a) & $\begin{array}{l}\text { Instituição/ } \\
\text { programa }\end{array}$ & Ano de defesa \\
\hline $\begin{array}{c}\text { Maria } \\
\text { Conceição } \\
\text { Borba }\end{array}$ & M & $\begin{array}{c}\text { Tânia Regina } \\
\text { Raitz }\end{array}$ & $\begin{array}{l}\text { UNIVALI/ } \\
\text { Educação }\end{array}$ & 2010 \\
\hline $\begin{array}{c}\text { Ana Paula R. } \\
\text { Freitas }\end{array}$ & M & $\begin{array}{l}\text { Rosangela G. } \\
\text { Pieto }\end{array}$ & USP/Educação & 2010 \\
\hline $\begin{array}{l}\text { Lúcia M. } \\
\text { Santos Tinós }\end{array}$ & $\mathrm{D}$ & $\begin{array}{c}\text { Fátima E. } \\
\text { Denari }\end{array}$ & $\begin{array}{c}\text { UFSCar/Educação } \\
\text { Especial }\end{array}$ & 2010 \\
\hline
\end{tabular}

Revista Educação Especial | v. 31 | n. 62 | p. 587-602 | jul./set. 2018

Santa Maria

Disponível em: <https://periodicos.ufsm.br/educacaoespecial> 


\begin{tabular}{|c|c|c|c|c|}
\hline $\begin{array}{l}\text { Taisa G. G. } \\
\text { Liduenha } \\
\text { Gonçalves }\end{array}$ & $M$ & $\begin{array}{l}\text { Silvia M. F. } \\
\text { Meletti }\end{array}$ & UEL/Educação & 2012 \\
\hline $\begin{array}{c}\text { Dulciana de C. } \\
\text { Lopes Dantas }\end{array}$ & $\mathrm{D}$ & $\begin{array}{c}\text { Lúcia de A. R. } \\
\text { Martins }\end{array}$ & $\begin{array}{c}\text { UFRN/ } \\
\text { Educaçấo }\end{array}$ & 2012 \\
\hline $\begin{array}{c}\text { Sandra C. M. } \\
\text { de Souza }\end{array}$ & M & $\begin{array}{c}\text { Ana D. B. de } \\
\text { Melo. }\end{array}$ & $\begin{array}{c}\text { UFPB/ } \\
\text { Educaçấo }\end{array}$ & 2013 \\
\hline $\begin{array}{c}\text { Monica Dias } \\
\text { de Araújo }\end{array}$ & $\mathrm{M}$ & $\begin{array}{c}\text { Ivanilde A. de } \\
\text { Oliveira }\end{array}$ & $\begin{array}{c}\text { UEPA/ } \\
\text { Educaçấo }\end{array}$ & 2013 \\
\hline Clarissa Haas & $M$ & $\begin{array}{c}\text { Claudio R. } \\
\text { Baptista }\end{array}$ & $\begin{array}{l}\text { UFRGS/ } \\
\text { Educaçấo }\end{array}$ & 2013 \\
\hline $\begin{array}{l}\text { Reni Gomes } \\
\text { Da Silva }\end{array}$ & $\mathrm{D}$ & $\begin{array}{c}\text { Alda Junqueira } \\
\text { Marin }\end{array}$ & $\begin{array}{l}\text { PUC-SP/ } \\
\text { Educação }\end{array}$ & 2013 \\
\hline $\begin{array}{l}\text { Taisa G. G. } \\
\text { Liduenha } \\
\text { Gonçalves }\end{array}$ & $M$ & $\begin{array}{l}\text { Katia R. M. } \\
\text { Caiado }\end{array}$ & $\begin{array}{c}\text { UFSCar/ } \\
\text { Educação } \\
\text { Especial }\end{array}$ & 2014 \\
\hline $\begin{array}{l}\text { Marcia da Silva } \\
\text { Freitas }\end{array}$ & $\mathrm{M}$ & $\begin{array}{c}\text { Marcia Soares } \\
\text { de Alvarenga }\end{array}$ & $\begin{array}{c}\text { UERJ/ } \\
\text { Educaçấo }\end{array}$ & 2015 \\
\hline $\begin{array}{l}\text { Marcia Roxana } \\
\text { Cruces Cuevas }\end{array}$ & $\mathrm{D}$ & Hiran Pinel & $\begin{array}{c}\text { UFES/ } \\
\text { Educaçáo }\end{array}$ & 2015 \\
\hline $\begin{array}{c}\text { Fabiana de } \\
\text { Oliveira Lima }\end{array}$ & $M$ & $\begin{array}{c}\text { Nilson Rogerio } \\
\text { da Silva }\end{array}$ & $\begin{array}{l}\text { UNESP- } \\
\text { Marília/ } \\
\text { Educação }\end{array}$ & 2015 \\
\hline $\begin{array}{c}\text { Flavya H. } \\
\text { Adamkosky } \\
\text { Botti }\end{array}$ & $M$ & $\begin{array}{c}\text { Edna Castro de } \\
\text { Oliveira }\end{array}$ & $\begin{array}{c}\text { UFES/ } \\
\text { Educação }\end{array}$ & 2016 \\
\hline
\end{tabular}

Fonte: Banco de Teses da CAPES. Elaboraçáo das autoras.

Ao identificar as temáticas dos 14 trabalhos que apresentaram a interface, verificamos que quatro pesquisas trataram da escolarizaçáo na EJA, três do direito à educação e duas das trajetórias escolares. As outras temáticas que apareceram individualmente foram: educação e trabalho; jovens e adultos com deficiência no campo; formação de professores; matrículas de alunos da Educação Especial na EJA; ensino médio na EJA.

\section{Trajetórias escolares}

Tinós (2010) visou compreender as trajetórias escolares de alunos com deficiência a partir dos entendimentos fenomenológicos para desvelar as vivências e os significados das percepçóes de cada participante no contexto vivido. Os dados possibilitaram entender aspectos dos serviços educacionais (escola especial, classe especial, 
classe regular e salas de EJA). A pesquisa sinaliza a fragilidade na legislação, apesar de alguns avanços referentes à garantia do direito à educação de qualidade para os alunos com deficiência que estão na EJA.

Haas (2013) analisou a interlocução que existe entre a EJA e a EE por meio da construção de narrativas associadas às trajetórias de vida de três jovens com deficiência matriculados na EJA. O foco principal foi a trajetória escolar dos sujeitos. A conclusão da autora, embasada nas narrativas, foi a necessidade de perceber o jovem e o adulto com deficiência para além de suas condiçôes orgânicas, de vê-los como sujeitos com possibilidades amplas e singulares de viver e aprender, uma vez que estas possibilidades são afetadas pelo contexto social em que estão inseridos.

\section{Matrículas de alunos da Educação Especial na EJA}

Gonçalves (2014) analisou as matrículas de alunos com Necessidades Educacionais Especiais (NEE) na EJA, no Brasil. Os resultados mostraram um alto índice de alunos com deficiência nas séries iniciais da EJA; uma concentração de matrículas de alunos com deficiência física e deficiência intelectual em espaços segregados; um alto percentual de matrículas de alunos com deficiência intelectual nessa modalidade; a juvenilização e o surgimento da EJA especial.

\section{Escolarização na EJA}

A pesquisa de Dantas (2012) investigou as concepçôes de professores e alunos sobre aspectos que se apresentam nos processos de escolarização de pessoas com deficiência intelectual na EJA e que repercutem nas configuraçôes de inclusão dessas pessoas nessa modalidade educacional.Constatou o desconhecimento, o preconceito e a negatividade nas concepçôes expressas pelos participantes sobre a inclusão na EJA e sobre os alunos com deficiência. Esses fatores destacam-se como condição definidora de limites e dificuldades educacionais enfrentados por alunos e professores, restringindo as possibilidades de convívio social

Araújo (2013) analisou como a escola de ensino fundamental vem incluindo alunos com necessidades educacionais especiais na EJA. Os resultados indicaram que o processo de inclusão escolar vem se manifestando de forma contraditória entre o que está determinado pelas leis e o estabelecido nas políticas educacionais. $\mathrm{Na}$ prática, o que se concretiza é que o atendimento educacional especializado não está priorizado para jovens e adultos com necessidades educacionais especiais na escola pesquisada. Mais uma vez, fica evidente a presença de alunos com deficiência que foram excluídos do ensino regular e se encontram presentes na EJA.

Baseando-se no olhar das professoras, Souza (2013) analisou o processo de inclusão de jovens e adultos com deficiência na EJA e investigou os tipos de deficiência existentes nas escolas que apresentam essas dificuldades. Os resultados indicaram a existência de um desequilíbrio entre as políticas inclusivas e as políticas da EJA, fortalecendo o surgimento de práticas que não condizem com a realidade dos alunos. A pesquisa possibilitou mostrar, também, que vem ocorrendo um conside- 
rável aumento de alunos com deficiência matriculados nessa modalidade de ensino, demonstrando que a EJA tornou-se um espaço de inserção para alunos que foram excluídos do ensino regular.

Lima (2015) caracterizou o perfil do aluno da EJA em um município do interior paulista, entre os anos de 2011 e 2013, e descreveu as práticas pedagógicas desenvolvidas com os alunos com deficiência. Os resultados indicam a predominância de mulheres e idosos na EJA, no munícipio. Com relação ao aluno com deficiência nessa modalidade de ensino, a autora identificou uma ampliação das matrículas, sobretudo por jovens do sexo masculino, tendo destaque a deficiência intelectual.

\section{Educação e trabalho}

Borba (2010) investigou os desafios e superaçóes na relação entre educação inclusiva e trabalho. A autora realizou uma pesquisa sobre as experiências de jovens com deficiência, a fim de analisar a forma como os jovens com deficiência enfrentam os desafios na relação que se estabelece entre educação inclusiva e trabalho, na sociedade contemporânea. Chegou à conclusão de que o trabalho e a educação influenciaram na construção das experiências pessoais, profissionais e sociais dos jovens entrevistados. Os territórios escolares e profissionais, o trabalho, o emprego, a formação e o pertencimento a grupos (familiares e amigos) são esferas consideradas legítimas e pertinentes na constituiçáo de categorias sociais, porque são responsáveis pelo modo como os jovens com deficiência se identificam e sáo identificados socialmente.

\section{Jovens e adultos com deficiência no campo}

Gonçalves (2014) analisou o processo de escolarização dos sujeitos com deficiência que frequentaram a EJA no campo. A autora verificou a interface entre as temáticas EE, EJA e educação no campo nos indicadores sociais, na produção acadêmica e na legislação. Também realizou entrevistas com alunos com deficiência que frequentaram a EJA no campo. O estudo revelou a interface entre as temáticas, porém, com pouca produção acadêmica e dificuldades no processo de escolarização desses sujeitos, as quais envolvem o âmbito político, financeiro e de execução prática e pedagógica, demonstrando a invisibilidade de jovens e adultos com deficiência que vivem em áreas rurais.

\section{Formação de professores}

Cuevas (2015) focou na formação de educadores inclusivos que trabalham na EJA. Para tanto, realizou uma cartografia das açôes e criaçóes de professores de uma escola pública de ensino fundamental de EJA que trabalham, nos três turnos, com pessoas de camadas populares que tiveram negado o seu direito de estudar. Contrapondo-se à formação docente na conjuntura neoliberal, a autora destaca que o encontro da EJA e da EE pela via da formaçáo inventiva, ética e política se apresenta como um caminho que poderá incidir sobre uma educação pública e de qualidade para todos. 


\section{Ensino médio na EJA}

Silva (2013) analisou os limites e possibilidades da inclusão escolar de alunos deficientes no ensino médio nas modalidades EJA/EE. O campo empírico foi uma escola na capital do estado de São Paulo, reconhecida como inclusiva por atender um significativo número de alunos com deficiência. Os procedimentos de pesquisa foram: levantamento bibliográfico, análise documental e questionários, respondidos por 12 alunos e nove professores. Os resultados da pesquisa indicaram a manutenção ou criação de um conjunto de impedimentos de ordem organizacional, política e burocrática, que geralmente produzem obstáculos à sua efetivação educacional. A autora conclui que o Estado deve investir na EJA por meio de organização administrativo-burocrática, com financiamento e diálogo entre os formuladores, os executores e os destinatários das ações.

\section{Direito à educação}

Freitas (2010) analisou o direito à EJA para pessoas com deficiência na legislação nacional e os principais programas e projetos adotados pelo município de São Paulo para garantir o direito à EJA após a Constituição Federal de 1988. Constatou que muitos jovens e adultos com deficiência continuam invisíveis para esses programas de políticas públicas e que sequer existe uma articulação entre as políticas das áreas da EJA e da EE. Aliás, no que se refere a esse assunto, ficou constatado que há um longo caminho a ser percorrido até que ocorra, efetivamente, uma educação de qualidade para os alunos que estão na EJA e apresentam alguma deficiência.

Por sua vez, Freitas (2015) analisou a interrelação entre EJA e EE no campo do direito à educação, no âmbito das políticas públicas. A pesquisa teve como foco o município de Itaboraí, no Rio de Janeiro, e baseou-se em dados quantitativos da Secretaria Municipal de Educação e Cultura de Itaboraí e em entrevistas semiestruturadas com componentes das equipes diretivas, com professores e funcionários de unidades escolares e com profissionais que atuam na Secretaria de Educação. Dentre os principais desafios a serem enfrentados em relação à EJA, no município, destacamse superar a evasão escolar, modificar o tratamento infantilizado dado ao público inserido nessa modalidade e promover melhorias na qualidade das escolas e nos atendimentos.

Botti (2016) estudou como se configuram as interfaces da EJA e da EE nas escolas da rede estadual de ensino do município de Colatina, no Espírito Santo, no que se refere à efetivação do direito à educação. Para tanto, realizou uma análise documental dos preceitos legais da educação como direito social, efetuou uma observação participante, elaborou um diário de campo, aplicou questionários e promoveu um levantamento de dados no IBGE. Os resultados da pesquisa revelaram um número reduzido de alunos com deficiência na EJA no munícipio e sinalizou que esses sujeitos estão matriculados, especificamente, em um Centro de Educação Estadual de Jovens e Adultos (Ceeja). Além disso, a autora destacou que a interface entre EE e EJA vem sendo construída pelos próprios alunos ao invés da implementação de políticas públicas. 
Em síntese, os trabalhos apresentados indicaram a não efetivação do direito à educação, trajetórias escolares descontínuas com o retorno à EJA, falta de atendimento educacional especializado, precária formação docente e políticas públicas que não tratam dos jovens e adultos público-alvo da EE na EJA. Ferraro e Dutt-Ross (2017, p. 1) exemplificam esse cenário, ao afirmarem que, no Brasil, em 2010, havia " 3,2 milhóes de crianças e adolescentes de 4 a 17 anos fora da escola (excluídos da escola) e outros sete milhóes com dois ou mais anos de defasagem nos estudos (de excluídos na escola)". Diante disso, a EJA poderia abarcar essas pessoas. Porém, há que se questionar o porquê da exclusão atual da e na escola.

Nesse direcionamento, buscamos compreender a percepção dos alunos com deficiência sobre a EJA, o significado desse espaço para eles e as suas perspectivas futuras.

\section{A realidade da EJA Especial: relatos dos alunos}

A escola estadual, lócus da pesquisa, apresenta 60 matrículas de alunos público-alvo da EE que frequentam a EJA Especial. A seleção dos participantes se deu por indicaçáo dos professores da escola.

Por questóes éticas, referenciaremos os participantes da pesquisa pelos nomes fictícios, Luísa e Vicente.

Luísa, 32 anos, apresenta deficiência intelectual e física, cursa o ensino médio na EJA Especial. A aluna teve uma trajetória escolar com várias interrupçôes devido ao tratamento de saúde e não teve nenhum acompanhamento educacional hospitalar. Atualmente, Luísa vive sozinha após a morte de seu pai e o desaparecimento da mãe.

Vicente, 36 anos, também apresenta deficiência intelectual e física. Concluiu o ensino médio na EJA Especial, na escola em que a pesquisa foi realizada. Tendo o apoio da mãe durante a trajetória escolar, revelou o desejo de cursar Pedagogia no ensino superior.

Ao perguntar sobre o processo de escolarização na EJA Especial, os participantes destacaram quatro aspectos: o olhar sobre a pessoa com deficiência; o abandono da EJA pelos colegas; o atendimento educacional especializado; o significado da EJA para perspectivas futuras.

As falas dos participantes indicam um olhar ainda pautado nos aspectos orgânicos e de constituição biológica da deficiência.

Eu tinha dificuldade quando eu tinha mãe porque ela me protegia. Minha máe dava tudo na máo, tudo (...). Depois que eu fiquei sem minha mãe tive que aprender a cozinhar, a lavar, a cuidar de uma casa. Hoje eu moro sozinha, recebo o beneficio do INSS${ }^{4}$ todo mês, vou ao banco receber, pago as contas de casa, faço a compra de mercado. (Luísa).

(...) teve uns que perguntaram: por que você estuda? você tem $\mathrm{BPC}^{5}$, você tem tudo. Você não precisa estudar, você é um deficiente físico, é um cadeirante, muitos me falaram isso. Falei: gente 
isso para mim é discriminação, isso não é legal, porque a própria pessoa já se sente um pouco discriminada e se vocês falarem isso não vai ser legal para mim porque o primeiro pensamento que passa pela nossa cabeça quando a gente vai à uma escola é como os alunos váo receber a gente, como vai ser feita essa inclusáo? (Vicente).

Ao enfatizar mais as relaçóes sociais e o processo educacional da pessoa com deficiência, ao invés dos aspectos orgânicos, deve estar claro que a função da escola para esses sujeitos não se resume à "socialização".

Independente das peculiaridades desses alunos, a educação a eles destinada deve revestir-se dos mesmos significados e sentidos que ela tem para os alunos que náo apresentam deficiência; para eles, como para com qualquer outro aluno, deve ser reconhecida a importância dos espaços de interação que o sistema educacional pode promover de forma sistemática na apropriação do conhecimento escolar e no desenvolvimento pessoal (FERRREIRA; FERREIRA, 2013, p. 39).

Luísa também revela suas percepçóes a respeito da sua professora licenciada em Química sobre os alunos com deficiência na EJA.

(...) comecei a fazer aula de química na terça-feira, não sei nada de química (...). A primeira aluna, assim (com deficiência), que a professora de química vai pegar ... Ela já teve outro aluno no ano passado, o Lucas ${ }^{6}$. Ela vai começar a trabalhar o mesmo conteúdo que ela trabalhou com o Lucas, ela vai trabalhar comigo só que em situaçôes diferentes, em dificuldades diferentes (Luísa).

A Resolução CNE/CP no 1/02 (BRASIL, 2002) estabelece que as instituições de ensino superior devem organizar a estrutura curricular de formação docente, o atendimento à diversidade, contemplando os alunos público-alvo da EE. Diante disso, Pedroso, Campos e Duarte (2013), ao analisaram as ementas dos cursos de licenciatura em Ciências Biológicas de três universidades estaduais e dos cursos de licenciatura em Química de uma universidade estadual e de uma universidade federal indicaram que houve reorganização curricular na perspectiva das políticas de inclusão, com o afastamento da realidade das escolas públicas e sem a menção dos conteúdos da área da EE. Isso pode ilustrar a dificuldade do professor licenciado ao se deparar com o processo de ensino-aprendizagem, dos alunos com e sem deficiência. Além disso, há professores que estão na escola desde antes da vigência da referida resolução (BRASIL, 2002) e que necessitam de uma formação continuada. Gatti (2010), ao especificar a análise nos currículos de 71 licenciaturas de Pedagogia no Brasil, evidenciou que 3,8\% das disciplinas, em seu conjunto, referem-se à área da EE e que poucos cursos realizam aprofundamento da temática com oferta de disciplinas optativas ou tópicos especiais no campo da EJA (1,6\%).

Outro assunto tratado por Luísa é o abandono da EJA pelos colegas.

Tem alunos que entraram na mesma época que eu (na EJA Especial), que poderiam estar terminando junto comigo ou até antes (Luísa). 
Nas palavras de Haddad (2007, p. 204- 205),

(...) a evasão escolar, reconhecidamente elevada em programas de EJA, em função não só de fatores internos aos processos de ensino-aprendizagem, provocados pelas dificuldades inerentes a essa modalidade de educação, mas também por fatores externos vinculados às difíceis condiçóes de vida dos alunos. Para superar tais dificuldades, é importante que ocorram incentivos à permanência dos alunos.

Além disso, há outro ponto que merece destaque na EJA: a descontinuidade das políticas, o que inviabiliza o avanço da educação brasileira. "Portanto, a política educacional precisa levar em conta essa peculiaridade e formular metas náo apenas de curto mas de médio e longo prazo e instituir propostas que possam, de fato, ser implementadas e avaliadas (...)" (SAVIANI, 2008, p. 271).

Outra temática apresentada pelos participantes foi o atendimento educacional especializado realizado na própria escola, durante o horário de aula.

(...) quando estou com alguma dificuldade, senta eu, o professor da disciplina mais a professora de apoio para discutir o material, o conteúdo que tem que ser trabalhado na sala (Luísa).

(...) elas (as professoras do atendimento educacional especializado) deixam o aluno se descobrir. E o que aconteceu? A Laura ${ }^{7}$ (professora) sentava ao meu lado e esperava que eu fizesse a atividade. Eu falava: "Mas, poxa! Eu não consigo fazer isso aqui! Por que tenho a professora do meu lado? Eu achava que ela tinha que fazer para mim e, do mesmo jeito, foi com a Paula ${ }^{8}$, com as duas eu penei um pouquinho. Só fui entender depois que eu me reuni com a pedagoga, a diretora, e elas me explicaram o papel do professor de apoio (Vicente).

Com a vinda dos alunos público-alvo da EE para a EJA, o atendimento educacional especializado (AEE) deve ser ofertado no contraturno, na forma complementar para os alunos com deficiência e transtornos globais do desenvolvimento e na forma suplementar para os que apresentam altas habilidades/superdotação. Entretanto, os estudos de Campos e Duarte (2011) e de Araújo (2013) revelam que, na realidade, essa efetivaçáo não ocorre para todos alunos da EE que frequentam a EJA.

Os participantes elucidaram o significado da EJA para perspectivas futuras.

(...) meu pai antes de falecer falava que eu não ia ser ninguém. Eu coloquei na minha cabeça que meu grande sonho é ser juíza promotora de justiça (...). Para resumir, de tudo que eu passei nos meus 32 anos, o que eu tenho mais orgulho é da escola (Luísa).

Entấo, devido à minha vontade, muito grande, de cursar Pedagogia (...). Só que agora eu te pergunto como eu vou concorrer com um milhão de jovens? (...) Não estou desmerecendo o Enem. Acho que o Enem é um ótimo suporte para a gente fazer, dá muita chance (...). Até estou querendo fazer um projeto que os alunos com necessidades especiais não precisem passar por um vestibular e Enem, porque o que acontece, esses exames exigem muito 
e, assim, na pontuação eles são muito rígidos. Então, qualquer pontinho que você fizer ou não fizer você se frustra, vai parar no hospital, fica doente. Acho que a universidade deveria me dar, quer dizer, não me dar, me dar uma chance de fazer o curso que eu quero, que é Pedagogia. Eu falo que a educação é o espelho dos meus olhos (Vicente).

Para mim, é um orgulho poder vir para escola. Quando eu entrei não queria nem saber de voltar a estudar (...). Olha onde eu estou hoje... Em dezembro, será minha formatura (Luísa).

Diante dessas falas, remetemos ao estudo de Caiado e Zeppone (2013), que apresenta histórias de pessoas com deficiência e a conclusão do ensino superior por elas, sem mencionarem as açôes assistenciais e se posicionarem como sujeitos de direitos.

A EJA pode ser um espaço de ressignificação escolar, com uma intencionalidade pedagógica e sem infantilização. Reconhecendo todos os alunos, com e sem deficiência, como sujeitos históricos, com perspectivas futuras decorrentes da apropriaçáo do conhecimento científico.

\section{Algumas considerações}

A interface entre EE e EJA vem sendo construída no cenário brasileiro. Porém, o que ainda nos inquieta é a estrutura política, organizacional e as práticas efetivas que interferem na vida de quem está matriculado na EJA.

Precisamos nos alertar para essa constituição da EJA aos alunos da EE, para que ela não se torne mais um espaço de segregação e desaparecimento do sujeito, assim como já aconteceu fortemente na área da EE com a presença de instituiçôes e classes especiais.

Consideramos que é preciso um rompimento com o assistencialismo presente na história da EE e na EJA. Desse modo, reforçamos que a educação é um direito e a escola tem uma função na sociedade, podendo transformar realidades a partir da apropriação do conhecimento produzido pelo homem. Esse conhecimento é nosso!

\section{Referências}

ARAÚJO, Monica Dias de. Tessituras da inclusão na Educaçáo de Jovens e Adultos no município de Altamira - Pará. 2013. 212 f. Dissertaçáo (Mestrado em Educação) - Universidade do Estado do Pará, Belém, 2013.

BRASIL. Constituiçáo da República Federativa do Brasil, 1988. Disponível em: <http://www.planalto.gov. br/ccivil_03/constituicao/constituicao.htm>. Acesso em: 29 abr.2018.

Brasil. Lei no 9.394, de 20 de dezembro de 1996. Estabelece as Diretrizes e Bases da Educaçáo Nacional. 1996.

2000.Resoluçáo CNE/CP no 1/2002, de 18 fevereiro de 2002. Institui Diretrizes Curriculares Nacionais para a Formaçáo de Professores da Educaçáo Básica, em nível superior, curso de licenciatura, de graduaçáo plena. Brasília: MEC/CNE, 2002. Disponível em: portal.mec.gov.br/arqui- vos/pdf/. Acesso em: 07 mai. 2018.

Ministério da Educação. Política Nacional de Educação Especial na Perspectiva da Educaçáo Inclusiva. Brasília: MEC, 2008. Disponível em <http://www.mec.gov.br> Acesso em: 05 mai. 2018.

BORBA, Maria Conceição. Desafios e superaçóes na relaçáo entre educaçáo inclusiva e trabalho: um estudo sobre as experiências de jovens com deficiência. 2010. 99 f. Dissertação (Mestrado em Educação) - Universidade do Vale de Itajaí, Itajaí, 2010. 
BOTTI, Flavya Herzog Adamkosky. Interfaces da educação de jovens e adultos e educaçáo especial: o direito em análise. 2016. 118 f. Dissertação (Mestrado em Educação)- Universidade Federal do Espírito Santo, Vitória, 2016.

CAIADO, Katia Regina Moreno. Aluno deficiente visual na escola: lembranças e depoimentos. Campinas: Autores Associados; PUC, 2003.

CAIADO, Katia Regina Moreno; ZEPPONE, Rosemeire Maria Orlando. Educação e deficiência na voz de quem viveu essa trama: apoios e atendimentos durante a trajetória escolar. In: JESUS, Denise Meyrelles de; BAPTISTA, Claudio Roberto; CAIADO, Katia Regina Moreno. (Org.). Prática pedagógica na Educaçáo Especial: multiplicidade do atendimento educacional especializado. 1 ed. v. 1. Araraquara, SP: Junqueira \& Marin, 2013. p. 235-252.

CAMPOS, Juliane Aparecida de Paula Perez; DUARTE, Márcia. O aluno com deficiência na EJA: reflexōes sobre o atendimento educacional especializado a partir do relato de uma professora da educaçáo especial. Revista Educaçáo Especial, Santa Maria, RS, v. 24, n. 40, p. 271-283, 2011.

CUEVAS, Marcia Roxana Cruces. Conversar e tensionar na formaçáo (des)continuada inventiva/inclusiva: cartografia de uma escola-território. 2015. 271 f. Tese (Doutorado em Educação)- Universidade Federal do Espírito Santo, Vitória, 2015.

DANTAS, Dulciana de Carvalho Lopes. A inclusão de pessoas com deficiência intelectual na Educaçáo de Jovens e Adultos (EJA): um estudo de caso. 2012. 288 f. Tese (Doutorado em Educaçăo) - Universidade Federal do Rio Grande do Norte, Natal, 2012

FERRARO, Alceu Ravanello. Analfabetismo no Brasil: desconceitos e políticas de Exclusão. Perspectiva, Florianópolis, v. 22, n. 1, p. 111-126, jan./jun. 2004.

FERRARO, Alceu Ravanello; DUTT-ROSS, Steven. Diagnóstico da escolarização no Brasil na perspectiva da exclusão escolar. Revista Brasileira de Educaçáo, v. 22, p. 01-26, 2017.

FERREIRA, Maria Cecília Carareto; FERREIRA, Júlio Romero. Sobre inclusão, políticas públicas e práticas pedagógicas. In: GÓES, Maria Cecília Rafael de; LAPLANE, Adriana Lia Friszman (Org.). Políticas e práticas de educaçáo inclusiva. Campinas, SP: Autores Associados, 2013. p.21-48.

FREIRE, Paulo. Educaçáo como prática da liberdade. 6 ed. Rio de Janeiro: Paz e Terra, 1976.

FREITAS, Ana Paula Ribeiro. A educaçáo escolar de jovens e adultos com deficiência: do direito conquistado à luta por sua efetivação. 2010. 202 f. Dissertação (Mestrado em Educação) - Universidade de São Paulo, São Paulo, 2010.

FREITAS, Marcia da Silva. Nas margens do direito à educaçáo: o enlace entre a Educaçáo de Jovens e Adultos e a Educação Especial no município de Itaboraí/RJ'. 2015.180f. Dissertaçáo (Mestrado em Educação)- Universidade do Estado do Rio de Janeiro, São Gonçalo, 2015.

GATTI, Bernardete. Formação de professores no Brasil: características e problemas. Educaçáo e Sociedade, Campinas, v. 31, n. 113, p. 1355-1379, out.-dez. 2010

GONÇALVES, Taísa Grasiela Gomes Liduenha. Alunos com deficiência na Educaçáo de Jovens e Adultos em assentamentos paulistas: experiências do PRONERA. 2014. 203 f. Tese (Doutorado em Educaçáo Especial) - Universidade Federal de São Carlos, São Carlos, 2014.

Escolarizaçáo de alunos com deficiência na Educaçáo de Jovens e Adultos: Uma análise dos indicadores educacionais brasileiros. 2012. 75 f. Dissertação (Mestrado em Educação) - Universidade Estadual de Londrina, Londrina, 2012.

GONÇALVES, Taísa Grasiela Gomes Liduenha; MELETTI, Silvia Márcia Ferreira; SANTOS, Natália Gomes. Nível instrucional de pessoas com deficiência no Brasil. Crítica Educativa, v. 1, p. 24-39, 2015.

HAAS, Clarissa. Narrativas e percursos escolares de jovens e adultos com deficiência: "Isso me lembra uma história!". 2013. 216 f. Dissertação (Mestrado em Educação) - Universidade Federal do Rio Grande do Sul, Porto Alegre, 2013.

HAAS, Clarissa; GONÇALVES, Taísa Grasiela Gomes Liduenha. Em tempos de democratização do direito à educação: como têm se delineado as políticas de acesso à EJA aos estudantes com deficiência no Rio Grande do Sul?. Revista Brasileira de Educação Especial, v. 21, p. 443-458, 2015.

HADDAD, Sérgio. A ação de governos locais na educação de jovens e adultos. Revista Brasileira de Educaçáo. v. 12, n. 35, p. 197-211, maio/ago. 2007. Disponível em: http://www.scielo.br/pdf/rbedu/v12n35/a02v1235. pdf. Acesso em: 07 ago. 2018. 
HAYASHI, Carlos Roberto Massao. Apontamentos sobre a coleta de dados em estudos bibliométricos e cientométricos. Filosofia e Educaçáo, Sáo Carlos, v. 5, p. 89-102, 2013.

Um estudo bibliométrico da produção científica sobre a educação jesuítica no Brasil colonial. Biblios: Revista Electrónica de Bibliotecología, Archivología y Museologia, ano 8, n. 27, p. 1-18, 2007.

LIMA, Fabiana de Oliveira. Experiências inclusivas na educaçáo de jovens e adultos em um município do interior paulista. 2015. 103f. Dissertação (Mestrado em Educação)- Universidade Estadual Paulista Júlio de Mesquita Filho, Marília, 2015.

MELETTI, Silvia Márcia Ferreira Meletti; RIBEIRO, Karen. Indicadores educacionais sobre a Educação Especial no Brasil. Cadernos CEDES, Campinas, v. 34, n. 93, p. 175-189, 2014.

PEDROSO, Cristina Cinto Araujo; CAMPOS, Juliane Aparecida de Paula Perez; DUARTE, Márcia . Formação de professores e educação inclusiva: análise das matrizes curriculares dos cursos de licenciatura. Educação Unisinos (Online), v. 17, p. 40-47, 2013.

SAVIANI, Dermeval. Educação socialista, pedagogia histórico-crítica e os desafios da sociedade de classes. In: LOMBARDI, José Claudinei; SAVIANI, Dermeval. (Org.) Marxismo e Educaçáo: debates contemporâneos. 2 ed. Campinas: Autores Associados; HISTEDBR, 2008.

SILVA, Márcia Regina da; HAYASHI, Carlos Roberto Massao; HAYASHI; HAYASHI, Maria Cristina Piumbato Innocentini. Análise bibliométrica e cientométrica: desafios para especialistas que atuam no campo. Revista de Ciência da Informaçáo e Documentação, v.2 n.1, p.110-129. 2011.

SILVA, Reni Gomes da. Limites e possibilidades da inclusáo escolar de deficientes no ensino médio modalidade Educaçáo de Jovens e Adultos: percepçóes de alunos e professores. 2013. Tese (Doutorado em Educação)- Pontifícia Universidade Católica de São Paulo, São Paulo, 2013.

SOUZA, Sandra Cristina Morais de. A educaçáo de jovens e adultos na perspectiva da inclusáo: o olhar das professoras. 2013. 122 f. Dissertação (Mestrado em Educação) - Universidade Federal da Paraíba, João Pessoa, 2013.

TINÓS, Lucia Maria Santos. Caminhos de alunos com deficiências à Educaçáo de Jovens e Adultos: conhecendo e compreendendo trajetórias escolares. 2010. 125 f. Tese (Doutorado em Educação Especial) -Universidade Federal de São Carlos, São Carlos, 2010.

\section{Notas}

${ }^{1}$ Disponível em: <http://www.capes.gov.br/component/content/article?id=2164>. Acesso em: mar. 2017.

${ }^{2}$ Gonçalves e Hayashi (2014) realizaram um estudo bibliométrico inicial sobre jovens e adultos com deficiência que estudavam em áreas rurais, no Banco de Teses e Dissertaçóes da Capes, com outras expressóes de busca, e identificaram 18 trabalhos que contemplavam, especificamente, a interface Educaçáo Especial e Educaçáo de Jovens e Adultos no período de 2003 a 2011. Desses trabalhos, apenas o de Gonçalves ( 2012) reincide na busca realizada neste estudo.

${ }^{3} \mathrm{O}$ projeto foi aprovado anteriormente pelo Comitê de Ética.

${ }^{4}$ Instituto Nacional de Seguro Social.

5 O Benefício de Prestação Continuada da Assistência Social.

${ }^{6}$ Pseudônimo.

${ }^{7}$ Nome fictício.

${ }^{8}$ Nome fictício.

\section{Agradecimentos}

Agradecemos ao Conselho Nacional de Desenvolvimento Científico e Tecnológico (CNPq) - Chamada pública Universal 01/2016- Projeto: 408454/2016-4 e à PROSUP/CAPES pelo suporte financeiro. 
Rosângela Martins Cabral - Luciane Guimarães Batistella Bianchini - Taisa Grasiela Gomes Liduenha Gonçalves

\section{Correspondência}

Rosângela Martins Cabral - Universidade Norte do Paraná. Av. Paris, 675 - Jardim Piza, Londrina - PR, CEP:86041-120.Londrina, Paraná, Brasil.

E-mail: rosangelacabral@seed.pr.gov.br - luannbi@hotmail.com - taisaliduenha@gmail.com

Recebido em 3 de janeiro de 2018

Aprovado em 28 de junho de 2018

\section{$@(1) \Theta$}

This work is licensed under a Creative Commons Attribution-NonCommercial 4.0 International (CC BY-NC 4.0) 